\title{
Analisis Faktor yang Berpengaruh terhadap Angka Kematian Ibu (AKI) di Kabupaten Jember Tahun 2018
}

\author{
Rossalina Adi Wijayanti ${ }^{1}$, Dahlia Indah Amareta ${ }^{1}$, Novita Nuraini ${ }^{1}$, Atma Deharja ${ }^{1}$, Gamasiano \\ Alfiansyah' ${ }^{1}$, Maya Weka Santi ${ }^{1}$ \\ ${ }^{1}$ Jurusan Kesehatan Politeknik Negeri Jember, Indonesia \\ e-mail: rossa.wijayanti@gmail.com
}

\begin{abstract}
Jember districts is one of the province in East Java which took second place for the highest Maternal Mortality Rate in 2016. The number of maternal mortality in Kabupaten Jember from 2014 until 2017 has increased, and in 2017 there were 43 mortalities. Public health center has a major and vital role as efforts to reduce maternal mortality rate in Indonesia. Health programs at the public health center are focused on preventive and promotive activities in the Maternal and Child Health program are not going well. The purpose of this research was to develop a strategy to reduce maternal mortality rate through the implementation of management of maternal health programs in public health center which included planning, organizing, actuating and controlling. This research used an observational analytic method with 34 public health centers as sample. The results of the study showed that planning and organizing had been carried out but in sufficient, actuating and controlling categories in the good category. There is a significant influence on the factors of organizing, actuating and controlling against maternal mortality rate. This research recommends to maintain activities to increase the coverage of pregnant women and maternity mothers, complete the job description for each job, increase cross-sector involvement in promotional activities, and maintain controlling activities.
\end{abstract}

Keywords : health programe, management, maternal mortality rate

\section{Pendahuluan}

Angka kematian ibu merupakan indikator kesejahteraan perempuan, indikator kesejahteraan suatu bangsa sekaligus menggambarkan hasil capaian pembangunan suatu negara. Informasi mengenai angka kematian ibu akan sangat bermanfaat untuk pengembangan program program peningkatan kesehatan ibu, terutama pelayanan kehamilan dan persalinan yang aman, program peningkatan jumlah persalinan yang ditolong oleh tenaga kesehatan, manajemen sistim rujukan dalam penanganan komplikasi kehamilan, persiapan keluarga hingga suami siaga dalam menyongsong kelahiran, yang pada gilirannya merupakan upaya menurunkan Angka Kematian Ibu dan meningkatkan derajat kesehatan reproduksi (Chalid, 2015).

Angka Kematian Ibu (AKI) di Indonesia masih cukup tinggi dan jauh berada di atas AKI negara ASEAN lainnya. Berdasarkan hasil laporan MDGs hasil Suvei Demografi dan Kesehatan Indonesia (SDKI) Tahun 2012 menunjukkan angka kematian ibu sebesar 359/ 100.000 Kelahiran Hidup (KH). Menurut profil kesehatan Indonesia Tahun 2015 Angka Kematian Ibu di Indonesia sebesar 305/100.000 KH (Hasil Survei Penduduk Antar Sensus).

Kabupaten Jember merupakan salah satu kabupaten yang terdapat di Propinsi Jawa Timur. Pada tahun 2016, Kabupaten Jember menduduki peringkat 2 (dua) untuk Angka Kematian Ibu tertinggi di Jawa Timur. Jumlah kematian ibu di Kabupaten Jember dari tahun 2014 sampai dengan tahun 2017 mengalami peningkatan. Angka Kematian Ibu (AKI) tahun 2014 sebanyak 31 kematian, tahun 2015 sebanyak 32 kematian, tahun 2016 sebanyak 33 kematian, dan pada tahun 2017 sebanyak 43 kematian (Dinas Kesehatan Kabupaten Jember, 2017).

Terdapat beberapa faktor penyebab kematian ibu, selain masalah medis banyak faktor yang memberikan kontribusi terhadap kematian ibu. Wijayanti (2001) menyatakan bahwa faktor yang memberikan kontribusi terhadap kematian ibu antara lain alat transportasi ke pusat rujukan yang masih rendah, pemberdayaan perempuan yang tidak begitu baik, masalah ketidaksetaraan gender, nilai budaya, latar belakang pendidikan, sosial ekonomi, lingkungan masyarakat dan politik, kebijakan serta rendahnya perhatian laki-laki terhadap ibu hamil dan melahirkan. Chalid 
(2015) menyebutkan penyebab kematian ibu masih berputar pada masalah utama (perdarahan, preklampsia-eklampsia dan infeksi), sehingga pencegahan dan penanggulangan masalah ini seharusnya difokuskan melalui intervensi pada ketiga masalah tersebut, melalui peran petugas kesehatan.

Berhasil tidaknya sebuah program besar kemungkinan dipengaruhi oleh pengelolaan dalam program tersebut. Hasil penelitian oleh Jati \& Sucipto (2006) menunjukkan bahwa adanya hubungan aspek manajemen petugas TB Paru Puskesmas Kabupaten Grobogan Provinsi Jawa Tengah dengan cakupan penemuan TB Paru pada Tahun 2003.

Terry (2006) menyatakan bahwa manajemen merupakan suatu proses yang khas, yang terdiri dari planning (perencanaan), organizing (pengorganisasian), actuating (penggerakan), controlling (pengawasan) yang dilakukan untuk menentukan serta mencapai sasaran yang telah ditentukan dengan memanfaatkan sumber daya manusia dan sumber daya lainnya. Sumber daya dasar dikelola oleh fungsi dasar manajemen agar supaya sasaran yang ditetapkan dapat dicapai. Oleh karena itu perlu dilakukan penelitian untuk menilai faktor-faktor manajemen yang mempengaruhi Angka Kematian Ibu (AKI) di Kabupaten Jember

\section{Metode}

Penelitian ini menggunakan metode observasional analitik. Metode ini digunakan dalam rangka perbaikan dan peningkatan program-program pelayanan kesehatan yang sedang dihadapi. Penelitian dilakukan pada Puskesmas di wilayah Kabupaten Jember, pada bulan April sampai dengan November 2018.

\subsection{Metode Pengumpulan Data}

Populasi dalam penelitian ini adalah Puskesmas di wilayah Kabupaten Jember, yaitu sebanyak 50 Puskesmas. Sampel dalam penelitian ini dihitung dengan rumus Slovin. Hasil perhitungan dengan menggunakan rumus Slovin didapatkan sampel sebesar 34 dan informan penelitian adalah penanggung jawab program kesehatan ibu di Puskesmas.
Teknik pengambilan sampel penelitian menggunakan propotional random sampling.

Pengumpulan data dilakukan memberikan kuisioner kepada informan kemudian selanjutnya digunakan untuk menyusun upaya untuk menurunkan AKI berdasarkan analisis faktor manajemen program kesehatan ibu di Puskesmas Kabupaten Jember.

\subsection{Metode Analisis Data}

Tahap analisis data dan penarikan kesimpulan, pada tahap ini data berupa angka dari informan akan dianalisis dengan bantuan software pengolahan data yang sesuai dengan skala data setiap variabel penelitian. Analisis data menggunakan uji regresi logistic. Tahap selanjutnya adalah merumuskan rekomendasi. Tahap ini adalah kegiatan yang dilakukan dalam merumuskan rekomendasi berupa upaya menurunkan AKI.

\section{Hasil dan Pembahasan}

Hasil penelitian tentang proses planning, organizing, actuating, dan controlling ditunjukkan oleh tabel berikut. Gsmbaran planning program kesehatan ibu Puskesmas Kabupaten Jember dapat dilihat tabel 1.

Tabel 1. Distribusi Planning Program Kesehatan Ibu Puskesmas di Kabupaten Jember Tahun 2018

\begin{tabular}{lcc}
\hline Planning & Frekuensi & $\begin{array}{c}\text { Persentase } \\
(\%)\end{array}$ \\
\hline Kurang & 0 & 0 \\
Cukup & 24 & 70,6 \\
Baik & 10 & 29,4 \\
$>65$ & 4 & 16,7 \\
\hline Total & 34 & 100 \\
\hline
\end{tabular}

Tabel 1 menunjukkan bahwa secara umum sebagian besar Puskesmas $(70,6 \%)$ telah melakukan planning program kesehatan ibu dalam kategori cukup. Gambaran organizing program kesehatan ibu puskesmas di Kabupaten jember dapat dilihat pada tabel 2. 
Tabel 2. Distribusi Organizing Program Kesehatan Ibu Puskesmas di Kabupaten Jember Tahun 2018

\begin{tabular}{lcc}
\hline Organizing & Frekuensi & $\begin{array}{c}\text { Persentase } \\
(\mathbf{\%})\end{array}$ \\
\hline Kurang & 1 & 2,9 \\
Cukup & 22 & 64,7 \\
Baik & 11 & 32,4 \\
\hline Total & 34 & 100,0 \\
\hline
\end{tabular}

Tabel 2 menunjukkan sebagian besar Puskesmas $(64,7 \%)$ telah cukup dalam melakukan organizing program kesehatan ibu. Namun demikian, hasil penelitian tersebut masih perlu dioptimalkan lagi mengingat hanya sebagian kecil Puskesmas (32,4\%) yang telah melakukan organizing dengan baik.

Gambaran Actuating program kesehatan ibu puskesmas di Kabupaten Jember dapat dilihat pada tabel 3 .

Tabel 3. Distribusi Actuating Program Kesehatan Ibu Puskesmas di Kabupaten Jember Tahun 2018

\begin{tabular}{lcc}
\hline \multicolumn{1}{c}{ Actuating } & Frekuensi & Persentase (\%) \\
\hline Kurang & 9 & 26,5 \\
Cukup & 7 & 20,6 \\
Baik & 18 & 52,9 \\
\hline Total & 34 & 100,0 \\
\hline
\end{tabular}

Tabel 3 di atas menjelaskan bahwa sebagian besar actuating program kesehatan ibu Puskesmas di Kabupaten Jember berjalan dalam kategori baik (52,9\%), kategori cukup $(20,6 \%)$, dan kategori kurang $(26,5 \%)$.

Gambaran Controlling program kesehatan ibu puskesmas di Kabupaten Jember dapat dilihat pada tabel 4 .

Tabel 4. Distribusi Controlling Program Kesehatan Ibu Puskesmas di Kabupaten Jember Tahun 2018

\begin{tabular}{lcc}
\hline \multicolumn{1}{c}{ Controlling } & Frekuensi & $\begin{array}{c}\text { Persentase } \\
(\mathbf{\%})\end{array}$ \\
\hline Kurang & 7 & 20,6 \\
Cukup & 8 & 23,5 \\
Baik & 19 & 55,9 \\
\hline Total & 34 & 100,0 \\
\hline
\end{tabular}

Tabel 4 menggambarkan bahwa sebagian besar Puskesmas (55,9\%) telah melakukan controlling program kesehatan ibu Puskesmas dengan kategori baik.
Hasil analisis faktor planning, organizing, actuating dan controlling program kesehatan ibu terhadap AKI puskesmas di kabupaten jember dapat dilihat pada tabel 5 .

Tabel 5. Hasil Analisis Faktor Planning, Organizing, Actuating dan Controlling Program Kesehatan Ibu terhadap AKI Puskesmas di Kabupaten Jember

\begin{tabular}{|c|c|c|}
\hline Variabel & $\begin{array}{c}\text { Sign } \\
\text { Hasil Uji }\end{array}$ & Kesimpulan \\
\hline Planning & 0,099 & $\begin{array}{l}\text { Tidak ada } \\
\text { pengaruh }\end{array}$ \\
\hline Organizing & 0,000 & Ada pengaruh \\
\hline Actuating & 0,000 & Ada pengaruh \\
\hline Controlling & 0,004 & Ada pengaruh \\
\hline
\end{tabular}

Berdasarkan Tabel 5 dapat diketahui faktor manajemen berpengaruh secara signifikan terhadap AKI Puskesmas di Kabupaten Jember. Namun, masih ditemukan faktor planning yang tidak berpengaruh.

Secara umum sebagian besar Puskesmas $(70,6 \%)$ telah melakukan planning program kesehatan ibu dalam kategori cukup. Hasil wawancara menunjukkan beberapa Puskesmas juga mengembangkan kegiatan dalam upaya perencanaan peningkatan cakupan ibu hamil berupa: kelas ibu hamil, koordinasi dengan PKK, aparat setempat, antar jemput ibu hamil dan bersaling menggunakan ambulan desa (gratis), pertemuan kader, membentuk kelompok RTK (Rumah Tangga Kelahiran), pelayanan terpadu ibu hamil (deteksi dini ibu hamil risti), kunjungan ke rumah dukun bermasalah.

Planning merupakan sesuatu hal yang sangat penting dan mendasari pelaksanaan kegiatan. Dengan melakukan planning diharapkan dapat mengotimalkan sumber daya yang dimiliki untuk mencapai tujuan yang diinginkan.

Sebagian besar Puskesmas (64,7\%) telah cukup dalam melakukan organizing program kesehatan ibu. Namun demikian, hasil penelitian tersebut masih perlu dioptimalkan lagi mengingat hanya sebagian kecil Puskesmas (32,4\%) yang telah melakukan organizing dengan baik.

Hasil identifikasi kegiatan organizing kegiatan program kesehatan ibu sudah dilengkapi dengan adanya job description dan 
alokasi sumber. Meskipun dalam job description masih belum dilengkapi deskripsi terpisah untuk masing masing posisi meliputi: kegiatan promosi, konseling ibu hamil dan bersalin, pemeriksaan ibu hamil dan bersalin, pengisian dan pemanfaatan Buku KIA, pendampingan Rujukan ANC jika diperlukan, pencatatan dan pelaporan.

Tidak adanya job description terpisah menyebabkan pekerjaan menjadi tumpang tindih. Tidak adanya pembagian kerja untuk masing masing pekerjaan dalam program kesehatan ibu dapat menjadi sebuah kendala dalam pelaksanaan program. Suatu pekerjaan tidak akan efektif jika dilakukan hanya oleh seorang karyawan (Daft, 2007).

Sebagian besar actuating program kesehatan ibu Puskesmas di Kabupaten Jember berjalan dalam kategori baik. Walaupun demikian, actuating program kesehatan ibu Puskesmas di Kabupaten Jember masih harus ditingkatkan lagi mengingat masih ditemukan sebanyak 9 Puskesmas (26,5\%) dalam kategori kurang.

Hasil identifikasi pada kualitas variabel actuating memberikan hasil beberapa variabel yang tercapai dalam kategori kurang. Sebagian besar Puskesmas masih memiliki keterlibatan lintas program, lintas sektor dan masyarakat yang kurang dalam kegiatan promosi. Sebagian besar kegiatan masih dilakukan oleh pihak puskesmas. Jati \& Sucipto (2006) menjelaskan bahwa tidak adanya kerjasama berhubungan dengan hasil dengan cakupan penemuan TB Paru Puskesmas Kabupaten Grobogan Provinsi Jawa Tengah pada tahun 2003.

Sebagian besar Puskesmas (55,9\%) telah melakukan controlling program kesehatan ibu Puskesmas dengan kategori baik. Namun masih ditemukan 7 Puskesmas (20,6\%) yang melakukan controlling program kesehatan ibu Puskesmas dalam kategori kurang. Hasil penelitian tersebut menunjukkan bahwa controlling program kesehatan ibu Puskesmas di Kabupaten Jember masih belum optimal hal ini menjadi kemungkinan penyebab ditemukannya Angka Kematian Ibu (AKI).

Wijayanti (2016) menyatakan bahwa controlling dalam penemuan pasien TB Puskesmas di Kabupaten Pasuruan masih belum optimal dapat mempengaruhi pencapaian CDR TB Puskesmas. Terry (2006) menyebutkan controlling dilakukan untuk menemukan, mengoreksi penyimpangan penting dalam hasil yang dicapai dari aktivitas yang direncanakan.

Hasil identifikasi AKI Puskesmas di Kabupaten Jember Tahun 2017 ditemukan kematian sebanyak 43 kasus. Besarnya kasus kematian terjadi pada 26 Puskesmas yang menjadi tempat penelitian. Berdasarkan hasil identifikasi faktor manajemen sebelumnya besar kemungkinan dipengaruhi oleh hasil penerapan faktor manajemen di Puskesmas.

Robbins \& Timothy (2008) menjelaskan kinerja merupakan hasil interaksi antara kemampuan, motivasi dan opportunity. Gambaran persaamaan tersebut manajemen merupakan penjabaran dari opportunity. Sehingga besar kemungkinan manajemen sangat mempengaruhi Angka Kematian Ibu (AKI). Faktor kesempatan (opportunity) merupakan faktor dominan yang mempengaruhi kinerja petugas dalam program penanggulangan TB (Syafei \& Hari, 2006). Hasil penelitian juga sejalan dengan Wijayanti \& Nuraini (2018) yang menyebutkan adanya hubungan antara faktor opportunity dan kinerja petugas program kesehatan ibu, yang berarti dengan kegiatan manajemen yang baik dapat menurunkan AKI.

Pengaruh faktor manajemen program kesehatan ibu terhadap hasil capaian Angka Kematian Ibu (AKI) Puskesmas di Kabupaten Jember diidentifikasi melalui uji regresi antara faktor manajemen terhadap AKI. Faktor manajemen faktor manajemen program kesehatan ibu terdiri dari planning (P), organizing $(\mathrm{O})$, actuating $(\mathrm{A})$ dan controlling (C).

Terry (2006) menjelaskan bahwa faktor manjemen tersebut adalah suatu proses. Pendapat tersebut menggambarkan bahwa faktor manajemen tidak dapat dipisahkan satu dengan yang lainnya. Sebuah praktek manajemen selalu mengaplikasikan faktor manajemen sebagai suatu proses yang saling terkait. Hasil uji regresi menunjukkan bahwa faktor manajemen yang terdiri dari planning, organizing, actuating dan controlling adalah suatu proses yang saling terkait dan tidak dapat dipisahkan satu dengan yang lainnya. Hasil analisis disajikan pada Tabel 5. 


\begin{abstract}
Berdasarkan Tabel 5 dapat diketahui faktor manajemen berpengaruh secara signifikan terhadap AKI Puskesmas di Kabupaten Jember. Namun, masih ditemukan faktor planning yang tidak berpengaruh. Kemungkinan besar faktor planning yang tidak berpengaruh karena setiap puskesmas telah melakukan kegiatan perencanaan yang baik. Hal ini sejalan dengan penelitian oleh Wijayanti \& Nuraini (2018) yang menyebutkan adanya hubungan antara faktor opportunity dan kinerja petugas program kesehatan ibu, yang berarti dengan kegiatan manajemen yang baik dapat menurunkan
\end{abstract} AKI.

Manajemen merupakan suatu proses yang khas, yang terdiri dari planning (perencanaan), organizing (pengorganisasian), actuating (penggerakan), controlling (pengawasan) yang dilakukan untuk menentukan serta mencapai sasaran yang telah ditentukan dengan memanfaatkan sumber daya manusia dan sumber daya lainnya (Terry, 2006). Sumber daya dasar dikelola oleh fungsi dasar manajemen agar supaya sasaran yang ditetapkan dapat dicapai. Pelaksanaan manajemen yang baik akan dapat menurunkan AKI.

Rekomendasikan menurunkan Angka Kematian Ibu (AKI) berdasarkan hasil analisis faktor manajemen program kesehatan ibu di puskesmas Kabupaten Jember Tahun 2018 terdiri dari: segi Planning tetap mempertahankan kegiatan dalam upaya perencanaan peningkatan cakupan ibu hamil berupa: kelas ibu hamil, koordinasi dengan PKK, aparat setempat, antar jemput ibu hamil dan bersaling menggunakan ambulan desa (gratis), pertemuan kader, membentuk kelompok RTK (Rumah Tangga Kelahiran), pelayanan terpadu ibu hamil (deteksi dini ibu hamil risti), kunjungan ke rumah dukun bermasalah. Planning merupakan sesuatu hal yang sangat penting dan mendasari pelaksanaan kegiatan.

Segi organizing, melengkapi job description dengan deskripsi terpisah untuk masing masing posisi meliputi: kegiatan promosi, konseling ibu hamil dan bersalin, pemeriksaan ibu hamil dan bersalin, pengisian dan pemanfaatan Buku KIA, pendampingan Rujukan ANC jika diperlukan, pencatatan dan pelaporan. Tidak adanya job description terpisah menyebabkan pekerjaan menjadi tumpang tindih. Meningkatkan keterlibatan lintas sektor dalam program melalui rapat. Melakukan evaluasi kecukupan alokasi sumberdaya program sebagai kebutuhan pelayanan minimal ibu hami dan ibu bersaling, agar tidak mengalami kekurangan.

Segi actuating, meningkatkan keterlibatan lintas program, lintas sektor dan masyarakat dalam kegiatan promosi melalui pertemuan. Segi controlling, mempertahankan kegiatan yang sudah baik dengan melakukan penjadwalan rutin agar dapat selalui terpantau.

\section{Simpulan dan Saran \\ 4.1 Simpulan}

Sebagian besar Puskesmas (70,6\%) telah melakukan planning program kesehatan ibu dalam kategori cukup. Sebagian besar Puskesmas (64,7\%) telah cukup dalam melakukan organizing program kesehatan ibu. Namun demikian, hasil penelitian tersebut masih perlu dioptimalkan lagi mengingat hanya sebagian kecil Puskesmas $(32,4 \%)$ yang telah melakukan organizing dengan baik.

Sebagian besar actuating program kesehatan ibu Puskesmas di Kabupaten Jember berjalan dalam kategori baik. Walaupun demikian, actuating program kesehatan ibu Puskesmas di Kabupaten Jember masih harus ditingkatkan lagi mengingat masih ditemukan sebanyak 9 Puskesmas (26,5\%) dalam kategori kurang.

Sebagian besar Puskesmas (55,9\%) telah melakukan controlling program kesehatan ibu Puskesmas dengan kategori baik. Namun masih ditemukan 7 Puskesmas (20,6\%) yang melakukan controlling program kesehatan ibu Puskesmas dalam kategori kurang. Hasil penelitian tersebut menunjukkan bahwa controlling program kesehatan ibu Puskesmas di Kabupaten Jember masih belum optimal.

Faktor manajemen berupa organizing (pengorganisasian), actuating (penggerakan), controlling (pengawasan) berpengaruh secara signifikan terhadap AKI Puskesmas di Kabupaten Jember. 


\subsection{Saran}

melalui Upaya menurunkan AKI dapat peningkatan cakupan ibu hamil dan ibu bersalin, melengkapai job description masing masing pekerjaan, meningkatkan keterlibatan lintas sektor pada kegiatan promosi, mempertahan kegiatan controlling.

\section{Daftar pustaka}

Chalid, M T. (2015). Upaya Menurunkan Angka Kematian Ibu: Peran Petugas Kesehatan. Departemen Obstetri dan Ginekologi. Fakultas Kedokteran. Universitas Hasanuddin.

Daft, RL. (2007). Management, Buku 1. Penerbit Salemba Empat, Jakarta.

Dinas Kesehatan Provinsi Jawa Timur. (2014). Profil Kesehatan Provinsi Jawa Timur 2014. Surabaya

Jati SP \& Sucipto E. (2006). Hubungan Aspek Manajemen Petugas TB Paru Puskesmas dengan Cakupan Penemuan TB Paru di Kabupaten Grobogan 2004. Jurnal Kesehatan Masyarakat FKM UNDIP, 4.

Kementerian Kesehatan RI. (2014). InfoDatin. Pusat Data dan Informasi Kementerian Kesehatan RI. Situasi Kesehatan Ibu. Jakarta.

Kementerian Kesehatan RI. (2015). Profil Kesehatan Indonesia Tahun 2015. Jakarta.

Robbins, SP \& Timothy, AJ. (2008). Perilaku Organisasi. Buku 1, Edisi 12. Salemba Empat. Jakarta.

Terry, GR. (2006). Asas Asas Menejemen. PT. Alumni. Bandung.

Wijayanti, RA. (2016). Analisis Faktor Manajemen di Puskesmas dalam Meningkatkan Case Detection Rate (CDR) Tuberkulosis, Jurnal Kesehatan, 4 (1).
Wijayanti, RA dan Nuraini, N. (2017). Analisis Faktor Petugas dalam Pengisian Kartu Ibu dan Alur Rujukan Ibu Hamil Risti. Prosiding Seminar Nasional Hasil Penelitian Tahun 2017, ISBN: 978-602-149175-1.

Wijayanti, RA dan Nuraini, N. (2018). Analisis Faktor Motivasi, Opportunity, Ability dan Kinerja Petugas Program Kesehatan Ibu di Puskesmas (Analysis of Motivation, Opportunity, Ability And Performance Maternal Health Programs In Puskesmas). Jurnal Manajemen Informasi Kesehatan Indonesia, 6 (1). 